\title{
Valuing mortality risk in the time of COVID-19
}

\author{
James K. Hammitt ${ }^{1,2}$
}

Accepted: 13 October 2020 / Published online: 11 November 2020

(C) Springer Science+Business Media, LLC, part of Springer Nature 2020

\begin{abstract}
In evaluating the appropriate response to the COVID-19 pandemic, a key parameter is the rate of substitution between wealth and mortality risk, conventionally summarized as the value per statistical life (VSL). For the United States, VSL is estimated as approximately \$10 million, which implies the value of preventing 100,000 COVID-19 deaths is $\$ 1$ trillion. Is this value too large? There are reasons to think so. First, VSL is a marginal rate of substitution and the potential risk reductions are non-marginal. The standard VSL model implies the rate of substitution of wealth for risk reduction is smaller when the risk reduction is larger, but a closed-form solution calibrated to estimates of the income elasticity of VSL shows the rate of decline is modest until the value of a non-marginal risk reduction accounts for a substantial share of income; average individuals are predicted to be willing to spend more than half their income to reduce one-year mortality risk by 1 in 100 . Second, mortality risk is concentrated among the elderly, for whom VSL may be smaller and who would benefit from a persistent risk reduction for a shorter period because of their shorter life expectancy. Third, the pandemic and responses to it have caused substantial losses in income that should decrease VSL. In contrast, VSL is plausibly larger for risks (like COVID-19) that are dreaded, uncertain, catastrophic, and ambiguous. These arguments are evaluated and key issues for improving estimates are highlighted.
\end{abstract}

Keywords Value perstatistical life $\cdot$ Pandemic $\cdot$ COVID-19·Age-dependence $\cdot$ Ambiguity aversion · Risk perception

JEL Classification $\mathrm{J} 17 \cdot \mathrm{Q} 51 \cdot \mathrm{D} 61 \cdot \mathrm{D} 91 \cdot \mathrm{H} 42 \cdot \mathrm{I10}$

James K. Hammitt

jkh@harvard.edu

1 Harvard University (Center for Risk Analysis \& Center for Health Decision Science), Cambridge, MA, USA

2 Toulouse School of Economics, University of Toulouse-Capitole, Toulouse, France 


\section{Introduction}

As societies try to judge what restrictions on normal activities should be taken to reduce the spread of pandemic SARS-CoV-2, a key parameter is the appropriate tradeoff between wealth or income and mortality risk. The usual approach to quantifying this tradeoff is the value per statistical life (VSL). In the United States, a value of about $\$ 10$ million is currently used when evaluating government regulations that affect environmental, health, and safety risks (Robinson et al. 2019). Using this value suggests it would be worthwhile for the U.S. population to sacrifice $\$ 1$ trillion, nearly $5 \%$ of U.S. GDP, to reduce the number of U.S. deaths from the pandemic by 100,000. With projections of U.S. deaths from COVID-19 in the absence of any control that have ranged as high as 2.2 million (Ferguson et al. 2020), it is possible that many hundreds of thousands of deaths could be prevented. Using figures like these (or smaller), Greenstone and Nigam (2020) estimated the benefits of reduced mortality from three to four months of moderate social distancing as $\$ 8$ trillion and Thunström et al. (2020) estimated the net benefits of social distancing in their base case as \$5 trillion, more than one-fifth of GDP. Hall et al. (2020) estimated the average American would be willing to give up more than one-third of a year's consumption to eliminate the mortality risk created by the pandemic if the average risk is 8 in 1000 and almost one-fifth if it is 3 in 1000 .

Is the conventional VSL appropriate for evaluating the benefits of preventing deaths from the pandemic? Is it too large? There are at least three reasons to think so: (1) VSL is the marginal rate of substitution of wealth for current mortality risk but the risk reductions achieved by controlling the pandemic are non-marginal and are valued at a lower rate; (2) COVID-19 mortality risk seems to be strongly concentrated among the elderly for whom VSL is arguably much smaller than for younger people; (3) the pandemic has caused substantial income losses, especially in some sectors, that decrease VSL. In contrast, other factors suggest the appropriate VSL should be larger for COVID-19 than for other risks, including the catastrophic and novel nature of the pandemic and ambiguity about the risk.

I address these issues in the following sections. Section 2 discusses the valuation of nonmarginal risks. I derive a novel closed-form solution for the value of a non-marginal risk reduction as a function of baseline survival probability, income, and the income elasticity of VSL. The solution reveals that the standard economic model underlying VSL, combined with estimates of how VSL varies with income, implies that the rate of willingness to pay for non-marginal risk reductions is well-approximated by VSL until the risk reduction is so large that willingness to pay accounts for a substantial fraction of income. Section 3 describes how VSL varies with age and finds that, while evidence is inconsistent, VSL is plausibly smaller at advanced ages. In addition, the value of a continuing risk reduction is smaller for people with shorter life expectancies who will expect to benefit for a shorter period. Section 4 evaluates the effect of lost current income and concludes the appropriate VSL for evaluating response policies is more sensitive to whether the pandemic causes sustained income losses than to any transient effects. Section 5 discusses some of the evidence about how VSL varies with qualitative attributes of how risk is perceived such as dread, uncertainty, and ambiguity; it suggests these factors may justify using a larger VSL to evaluate COVID-19 risks than for other risks but the evidence about how large an adjustment may be warranted is weak. Section 6 concludes. Note that some of the results, especially those concerning willingness to pay for non-marginal risk reductions, the smaller 
value of a continuing risk reduction to people with shorter life expectancies, and the effects of transient or permanent income losses on valuation, are applicable to other hazards and other contexts, as well as to the COVID-19 pandemic.

\section{Valuing non-marginal risk reduction}

The standard model underlying VSL assumes that each agent wishes to maximize her expected state-dependent utility (Drèze 1962; Jones-Lee 1974; Weinstein et al. 1980),

$$
U=s u_{a}(w)+(1-s) u_{d}(w)
$$

where $s$ is the probability of surviving the current period (e.g., the current year) and $u_{a}(w)$ and $u_{d}(w)$ are the (indirect) utility of wealth $w$ conditional on survival and death, respectively. Utility conditional on survival depends on the multivariate lottery over future longevity, health, income, and other factors that the individual will face if she survives. Utility conditional on dying in the current period, often called the bequest function, depends on utility during the part of the period she survives and on the utility she gains by bequeathing her assets to family members or others.

VSL is the marginal rate of substitution of wealth $w$ for survival probability $s$. Let $V(s, w)$ denote VSL as a function of survival probability and wealth. Differentiating Eq. (1) holding expected utility U constant yields

$$
V(s, w)=\frac{u_{a}(w)-u_{d}(w)}{s u_{a}^{\prime}(w)+(1-s) u_{d}^{\prime}(w)}=\frac{\Delta u(w)}{E u^{\prime}(w)}
$$

where primes denote derivatives. It is conventional and in most circumstances reasonable to assume $u_{a}(w)>u_{d}(w), u_{a}{ }^{\prime}(w)>u_{d}{ }^{\prime}(w) \geq 0, u_{a}{ }^{\prime \prime}(w) \leq 0$, and $u_{d}{ }^{\prime \prime}(w) \leq 0$. In words, at all wealth levels: survival is preferred to death, the marginal utility of wealth conditional on survival is larger than the marginal utility of a bequest, which is nonnegative, and the individual is weakly risk averse with respect to wealth conditional on survival and on death. Any effect of death on wealth, such as loss of future earnings or medical costs, can be incorporated into the definition of $u_{d}$. As shown by the last term in Eq. (2), VSL is equal to the difference in utility between surviving the period and dying divided by the expected utility cost of spending.

Under these assumptions, indifference curves between wealth and survival probability are downward sloping and convex (as illustrated in Fig. 1) and VSL is strictly positive. VSL is decreasing in survival probability, $\partial V / \partial s<0$, the so-called dead-anyway effect (Pratt and Zeckhauser 1996). This follows because an increase in $s$ has no effect on the numerator in Eq. (2) but increases the denominator by shifting weight from the (smaller) marginal utility of the bequest to the (larger) marginal utility of wealth conditional on survival. VSL is increasing in wealth, $\partial V / \partial w>0$, because an increase in wealth increases the numerator (the utility gain from survival increases with wealth; $\left.u_{a}{ }^{\prime}(w)>u_{d}{ }^{\prime}(w)\right)$ and decreases the denominator or leaves it unchanged (the opportunity cost of spending decreases or is unchanged with wealth; $u_{a}(w)$ and $u_{d}(w)$ are both weakly concave). As described in Section 4, because the utility of wealth conditional on survival depends on uncertain future conditions, 
anticipated losses in future earnings (e.g., due to persistent effects of the pandemic) decrease wealth and VSL. Similarly, expectations about the duration of the pandemic before an effective vaccine or treatment becomes widely available affect the utility conditional on survival; accelerating their expected arrival increases the value of surviving the current period and hence VSL.

The compensating surplus $v(\delta)$ (willingness to pay) for a non-marginal increase in survival from $s$ to $s+\delta(\delta>0)$ is an increasing, concave function of $\delta$, and hence the average rate of substitution between wealth and the survival gain, $v / \delta$, is a decreasing function of $\delta$. In words, the rate at which an individual will sacrifice wealth for an increment to survival probability decreases as the increment increases.

How quickly does the average rate of substitution $v / \delta$ fall as $\delta$ increases? Let $V_{0}$ denote $V\left(s_{0}, w_{0}\right)$ and $V_{1}$ denote $V\left(s_{1}, w_{1}\right)$ where $s_{1}=s_{0}+\delta$ and $w_{1}=w_{0}-v(\delta)$, as illustrated in Fig. 1. Because the indifference curve is convex, $\delta V_{0}>v>\delta V_{l}$. To determine the difference between $V_{0}$ and $V_{l}$, note that by the intermediate-value theorem

$$
V_{1}=V_{0}+\delta \frac{\partial V\left(s_{a}, w_{a}\right)}{\partial s}-v \frac{\partial V\left(s_{b}, w_{b}\right)}{\partial w}
$$

where the points $\left(s_{a}, w_{a}\right)$ and $\left(s_{b}, w_{b}\right)$ are on the indifference curve somewhere between $\left(s_{0}, w_{0}\right)$ and $\left(s_{1}, w_{1}\right)$ and may differ from each other. Hence the difference between $V_{l}$ and $V_{0}$ can be decomposed into a risk effect (that depends on the risk reduction $\delta$ ) and a wealth effect (that depends on the compensating surplus $v$ ). Both risk and wealth effects decrease VSL.

To evaluate the risk effect, hold wealth constant and evaluate the ratio

$$
\frac{V(s+\delta, w)}{V(s, w)}=\frac{s u_{a}{ }^{\prime}(w)+(1-s) u_{d}{ }^{\prime}(w)}{(s+\delta) u_{a}{ }^{\prime}(w)+\left(1-s^{-\delta}\right) u_{d}{ }^{\prime}(w)}>\frac{s}{s+\delta}
$$

where the inequality follows by recalling $u_{a}{ }^{\prime}(w)>u_{d}{ }^{\prime}(w) \geq 0$ and setting $u_{d}{ }^{\prime}(w)=0$. Hence the effect of an increase in survival probability is to decrease VSL by a factor no smaller than the ratio of the initial to the enhanced survival probability. Because the

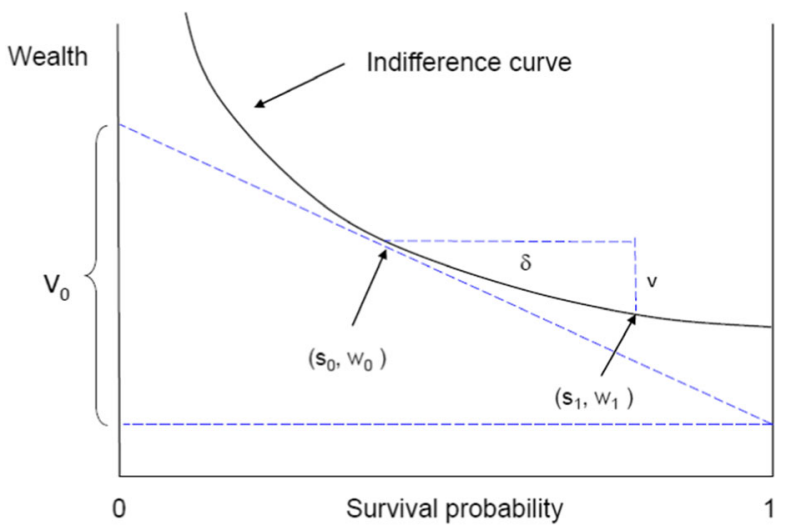

Fig. 1 Indifference curve and VSL 
enhanced survival probability cannot exceed one, the factor by which VSL is decreased is less than one and is no smaller than $s\left(s \leq \frac{s}{s+\delta}<1\right)$. The magnitude of the risk effect depends on the marginal utility of a bequest; it is largest when the marginal utility of a bequest is zero and decreases (to no effect) in the limit as the marginal utility of a bequest increases toward the marginal utility of wealth conditional on survival.

To evaluate the wealth effect, hold $s$ constant and evaluate the ratio

$$
\frac{V(s, w-v)}{V(s, w)}=\left(\frac{w-v}{w}\right)^{\gamma}=\left(1-\frac{v}{w}\right)^{\gamma}<1
$$

where $\gamma>0$ is the average wealth elasticity of VSL over the relevant range ( $\gamma$ need not be constant). ${ }^{1}$ The size of the wealth effect is sensitive to the wealth elasticity and the ratio of the compensating surplus to wealth. For a wealth elasticity of one (consistent with empirical evidence described below), VSL decreases in proportion to the compensating surplus measured as a share of wealth; if the wealth elasticity is larger than one, the decrease in VSL is larger than proportional.

Combining the risk and wealth effects yields the differential equation

$$
d w=-\frac{s_{0}}{s_{0}+\delta} V_{0}\left(\frac{w}{w_{0}}\right)^{\gamma} d \delta
$$

where the marginal utility of a bequest is assumed to be zero, maximizing the risk effect. Solving for $w(\delta)$ subject to the initial condition $w(0)=w_{0}$ yields

$$
w(\delta)=\left[w_{0}^{1-\gamma}-(1-\gamma) \frac{s_{0} V_{0}}{w_{0} \gamma} \log \left(1+\frac{\delta}{s_{0}}\right)\right]^{\frac{1}{1-\gamma}}
$$

for $\gamma \neq 1$ and

$$
w(\delta)=\exp \left[\log \left(w_{0}\right)-\frac{s_{0} V_{0}}{w_{0}} \log \left(1+\frac{\delta}{s_{0}}\right)\right]=w_{0} /\left(1+\frac{\delta}{s_{0}}\right)^{\frac{s_{0} V_{0}}{w_{0}}}
$$

for $\gamma=1$. Equations (7a) and (7b) describe the indifference curve passing through the point $\left(s_{0}, w_{0}\right)$ as a function of the wealth elasticity of VSL and assuming the marginal utility of a bequest is zero. If the marginal utility of a bequest is greater than zero, the indifference curve is steeper and willingness to pay to reduce risk is larger. ${ }^{2}$ If the wealth elasticity of VSL $\gamma$ is not constant, these equations describe the indifference curve $w(\delta)$ using the average wealth elasticity of VSL over the range between 0 and $\delta$ (where $\delta$ can be larger or smaller than zero).

\footnotetext{
${ }^{1}$ In general, the income elasticity $\gamma$ in Eq. (5) can depend on survival probability $s$, but not if the measure of risk aversion of the bequest function is equal to either the measure of risk aversion of utility conditional on survival or zero. Empirical estimates of income elasticity are for values of $s$ close to one.

${ }^{2}$ In the limit as $u_{d}^{\prime}(w) \rightarrow u_{a}^{\prime}(w)$, the equation for the indifference curve can be obtained from Eqs. (7a) and (7b) by substituting the term $\frac{V_{0}}{w_{0} \gamma} \delta$ for $s_{0} \frac{V_{0}}{w_{0} \gamma \log \left(1+\frac{\delta}{s_{0}}\right)}$. This substitution decreases $w(\delta)$ for $\delta>0$.
} 
The value of the wealth elasticity $\gamma$ is not well-determined. The standard model (1) implies it is positive, as discussed above. If the Arrow-Pratt measures of relative risk aversion (for risk to wealth) are equal for the state-dependent utility function conditional on survival and the bequest function (or if the bequest function is risk neutral, i.e., linear), then the wealth elasticity of VSL is strictly larger than the measure of relative risk aversion $-w u_{a}{ }^{\prime \prime}(w) / u_{a}{ }^{\prime}(w)$ (Eeckhoudt and Hammitt 2001; Kaplow 2005). Empirical estimates of relative risk aversion span a wide range, with minimum values around one and many estimates larger than five (Barseghyan et al. 2018). However, the conclusion that the income elasticity exceeds the coefficient of relative risk aversion does not hold in a richer model in which labor hours and income can be varied or there is a sufficient degree of complementarity between consumption and labor (Evans and Smith 2010).

Empirical studies have estimated the income elasticity, but rarely the wealth elasticity, of VSL, presumably because wealth data are rarely available. For most people, the difference may be of only modest importance; for U.S. households, median annual income is about $\$ 60,000$ and median wealth is about $\$ 95,000$ in total and $\$ 30,000$ excluding home equity (2016 estimates from U.S. Census Bureau). For some households, wealth is much greater than income. The difference between wealth and income can be important for evaluating willingness to pay to reduce mortality risk for a limited period as compared with willingness to pay for a continuing risk reduction. That is, individuals could pay more to reduce mortality risk from a one-time or infrequent hazard (such as a pandemic) than they could pay on a continuing basis for a persistent hazard (such as ambient air pollution or motor-vehicle crashes).

Income elasticity has been estimated using several methods (Hammitt and Robinson 2011). The most direct is to examine how estimated VSL varies with respondents' income in stated-preference studies. This approach generally yields estimates that are statistically significantly positive but less than one, in many cases less than one-half (e.g., between 0.1 and 0.4 in Corso et al. 2001, Alberini et al. 2004, and Hammitt and Haninger 2010, about 0.7 in Cameron and DeShazo 2013, between 0.2 and 0.6 in a set of studies in several countries reported by Hoffmann et al. 2017). Using self-reported tax payments of Swiss respondents to infer their wealth, Rheinberger (2011) estimated the wealth elasticity of VSL as 0.90 and 0.96 in alternative models.

Hedonic-wage studies usually do not estimate income elasticity because the dependent variable (the wage rate) is strongly correlated with income. Meta-analyses of these studies generally yield estimates of approximately 0.5 to 1.0 (Viscusi and Aldy 2003; Viscusi and Masterman 2017a, b). Meta-analyses of stated-preference studies also yield estimates of one or smaller. For example, Lindhjem et al. (2011) estimated values of 0.7 to 0.9 ( 0.3 to 0.4 using only studies that satisfy more stringent quality criteria) and Masterman and Viscusi (2018) estimated values of 0.94 to 1.05 overall but find evidence that the elasticity decreases with income; they estimated it is about 0.55 for higher-income and 1.0 for lower-income countries. A few studies suggest income elasticities substantially larger than one; e.g., in a hedonic-wage study using quantile regression, Kniesner et al. (2010) estimated an income elasticity of about 1.4, increasing from 1.2 in the highest income decile to 2.2 in the lowest decile.

Two studies have estimated VSL for a population at different points in time and found that it increased more rapidly than income; attributing the change in VSL to the change in income implies an elasticity greater than one. Costa and Kahn (2004) 
Table 1 Compensating surplus and average rate of substitution of wealth for mortality-risk reduction

\begin{tabular}{|c|c|c|c|c|c|c|}
\hline \multirow[b]{2}{*}{$\begin{array}{l}\text { Risk } \\
\text { reduction } \\
\delta\end{array}$} & \multicolumn{2}{|c|}{ Wealth elasticity $\gamma=1$} & \multicolumn{2}{|c|}{ Wealth elasticity $\gamma=3$} & \multicolumn{2}{|c|}{ Wealth elasticity $\gamma=10$} \\
\hline & $\begin{array}{l}\text { Compensating } \\
\text { surplus } v\end{array}$ & $\begin{array}{l}\text { Average rate } \\
\text { of } \\
\text { substitution } \\
v / \delta\end{array}$ & $\begin{array}{l}\text { Compensating } \\
\text { surplus } v\end{array}$ & $\begin{array}{l}\text { Average rate } \\
\text { of } \\
\text { substitution } \\
v / \delta\end{array}$ & $\begin{array}{l}\text { Compensating } \\
\text { surplus } v\end{array}$ & $\begin{array}{l}\text { Average rate } \\
\text { of } \\
\text { substitution } \\
v / \delta\end{array}$ \\
\hline
\end{tabular}

\begin{tabular}{lrrrrrr} 
Survival $s_{0}=0.99$ & & & & & \\
0.0001 & 992 & 9.92 & 976 & 9.76 & 925 & 9.25 \\
0.001 & 9210 & 9.21 & 8040 & 8.04 & 5810 & 5.81 \\
0.01 & 48,600 & 4.86 & 31,100 & 3.11 & 15,900 & 1.59 \\
Survival $s_{0}=0.5$ & & & & & \\
0.0001 & 1950 & 19.5 & 1890 & 18.9 & 1710 & 17.1 \\
0.001 & 16,900 & 16.9 & 13,400 & 13.4 & 8520 & 8.52 \\
0.01 & 57,700 & 5.77 & 38,100 & 3.81 & 18,900 & 1.89 \\
0.1 & 60,000 & 0.60 & 52,300 & 0.52 & 27,800 & 0.28 \\
\hline
\end{tabular}

Wealth $w_{0}=\$ 60,000$. Compensating surplus $(v)$ in $\$$, average rate of substitution $(v / \delta)$ in million $\$$

estimated VSL using hedonic-wage regressions for U.S. workers each decade from 1940 to 1980; comparing estimated VSL with per capita GNP implies an income elasticity of 1.5 to 2.0. Hammitt et al. (2019) conducted stated-preference studies using similar methods in Chengdu, China in 2005 and 2016; comparing estimated VSL with income growth over the period implies an elasticity of 3.0.

Table 1 presents illustrative calculations of compensating surplus and the average rate of substitution of wealth for survival probability for alternative risk reductions $\delta$ and baseline survival probabilities $s_{0}$. The calculations assume baseline VSL $V_{0}=\$ 10$ million and baseline survival probability $s_{0}=0.99$, slightly smaller than the one-year value for a 40 year old American (0.998, Arias and $\mathrm{Xu}$ 2019). Baseline wealth $w_{0}=\$ 60,000$ (i.e., U.S. median household income). This value is between the values of median wealth $(\$ 95,000)$ and median wealth excluding home equity $(\$ 30,000)$.

As is clear from the table, the average rate of substitution of wealth for survival probability does not decrease quickly before a large fraction of wealth has been spent. ${ }^{3}$ If the wealth elasticity is one, the average rate of substitution for an increase in survival $\delta=1 / 10,000$ is $\$ 9.9$ million; for increases of $1 / 1000$ and $1 / 100$ it is $\$ 9.2$ million and $\$ 4.9$ million, respectively. Equivalently, the individual would be willing to pay $\$ 990$ to decrease current-year mortality risk from 0.0100 to 0.0099 , more than $\$ 9000$ to

\footnotetext{
${ }^{3}$ Viscusi (2010) and Cardoso and Dahis (2020) also found that average rates of substitution for non-marginal risk reductions decrease only modestly as the risk reduction increases. Unlike the current approach, these authors assumed that utility conditional on survival exhibits constant relative risk aversion. Viscusi (2010) assumed utility is logarithmic (i.e., relative risk aversion equals 1), the bequest function is zero, baseline risk $=1 / 1000, \mathrm{VSL}=\$ 7$ million, and income $=\$ 27,200$. He calculated that willingness to pay to reduce risk by 9 in 10,000 is $\$ 5825$ (more than $20 \%$ of income), implying an average rate of substitution only $8 \%$ smaller than VSL. Cardoso and Dahis (2020) calculated the value of social distancing to protect against COVID mortality. For the U.S., with an average risk reduction of almost 4/100,000 and using a common VSL for all individuals, they calculated an average rate of substitution that is 9 or $15 \%$ smaller than VSL, assuming the measure of relative risk aversion equals 1 or 1.4 , respectively.
} 
decrease risk from 0.010 to 0.009 , and more than $\$ 48,000$ to eliminate the risk of dying in the current year.

While it is conceivable a household with wealth of $\$ 60,000$ might be able to spend $\$ 9000$ to reduce current mortality risk by $1 / 1000$, spending $\$ 48,000$ to eliminate the $1 /$ 100 risk seems implausible. For context, American households between the 50th and 60 th percentiles of pre-tax income (average pre-tax income $=\$ 62,000$, post-tax income $=\$ 57,000$, head of household age $=49$ years) have average annual expenditures of $\$ 54,000$. Average expenditures by category are $\$ 18,600(34 \%)$ on housing, $\$ 9400$ $(17 \%)$ on transportation, $\$ 7200(13 \%)$ on food, $\$ 5200(10 \%)$ on personal insurance and pensions, $\$ 4800(9 \%)$ on healthcare, $\$ 4000(7 \%)$ on utilities, $\$ 2400(4 \%)$ on entertainment, and $\$ 1700$ (3\%) on apparel. ${ }^{4}$ Spending tens of thousands of dollars on mortalityrisk reduction would require extreme cuts in some or all of these categories.

Increasing the income elasticity to three, at the high end of existing estimates, has only a modest effect: the average rates of substitution of wealth for survival probability decrease to $\$ 9.8, \$ 8.0$ and $\$ 3.1$ million for risk reductions of $1 / 10,000,1 / 1000$, and $1 / 100$, respectively. For a sufficiently large value of the income elasticity, the average rates of substitution fall more rapidly; when the income elasticity is 10 (much larger than existing estimates), the average rates of substitution are $\$ 9.2, \$ 5.8$, and $\$ 1.6$ million for risk reductions of $1 / 10,000,1 / 1000$, and $1 / 100$, respectively. Under these assumptions, the individual would pay almost $\$ 16,000$, more than one-quarter of wealth, to eliminate a mortality risk of $1 / 100$.

For a smaller baseline survival probability, VSL and the compensating surplus associated with a specified risk reduction increase because of the dead-anyway effect. For example, an individual's VSL might increase upon diagnosis of COVID-19 or another life-threatening illness. Decreasing baseline survival from 0.99 to 0.50 increases VSL by a factor equal to or smaller than the reciprocal of the ratio of survival probabilities (Eq. (4)), i.e., 0.99/0.5 or less. Taking the maximum value implies VSL with $s_{0}=0.5$ equals $\$ 19.8$ million. As shown in the bottom panel of Table 1 , the average rate of substitution of wealth for survival probability for each risk reduction is larger when baseline survival probability is smaller; nearly twice as large for small risk reductions but more similar to the previous values for larger risk reductions. With baseline survival equal to 0.5 , willingness to pay to increase survival probability by 1 / 100 is $\$ 58,000$ for an wealth elasticity of $1, \$ 38,000$ for an elasticity of 3 , and $\$ 19,000$ for an elasticity of 10 . Willingness to pay to increase survival probability from 0.5 to 0.6 is nearly equal to wealth for an income elasticity of 1 and 3, and almost half of wealth for an elasticity of 10 .

Sacrificing a large share of wealth to reduce mortality risk from a particular hazard (e.g., SARS-CoV-2) could lead to impoverishment and increases in other mortality risks. Health and longevity are positively correlated with income and wealth and there is a literature that estimates how decreases in income increase total mortality risk based on cross-sectional and longitudinal data (Wildavsky 1979, 1980; Keeney 1990, 1997; Chapman and Hariharan 1994, 1996; Broughel and Viscusi 2020). Viscusi (1994a, b) showed that the rate at which a marginal reduction of income increases mortality risk equals VSL divided by the individual's marginal propensity to spend on mortality-risk

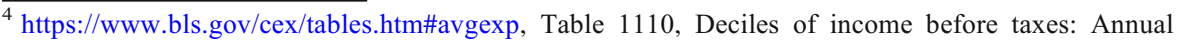
expenditure means, shares, standard errors, and coefficients of variation, Consumer Expenditure Survey, 2018.
} 
reduction; he estimated this marginal propensity as roughly 0.1 , which suggests the effect of paying $v(\delta)$ to reduce a particular risk by $\delta$ reduces total mortality risk by only $0.9 \delta$. For non-marginal reductions in wealth, the effect would presumably be larger. Equations $(7 \mathrm{a}, 7 \mathrm{~b})$ describe the compensating surplus for a reduction in total mortality risk, incorporating any offsetting increase in other mortality risks.

Empirical evidence about willingness to pay for large changes in mortality risk is limited. Many households are impoverished by medical spending, which suggests people do sacrifice a large share of wealth for health (more than $60 \%$ of personal bankruptcies in the U.S. are attributed to medical spending; Himmelstein et al. 2009). Shrime et al. (2018) found a large majority of survey respondents (from a nationally representative internet panel) valued a reduction in mortality risk more than an equal reduction in risk of bankruptcy. Respondents were asked to assume they had developed a fatal disease and to choose between paired treatments that presented different probabilities of cure and of financial solvency. Probabilities were randomly and independently varied over five levels $(0.10,0.25,0.50,0.75$, and 0.90$)$. On average, the value of an increase in the probability of cure was five times as large as the value of an equal increase in the probability of solvency. Using latent class analysis to explore preference heterogeneity produced five classes. Compared with the outcome dead and bankrupt, the largest class (with membership probability $31 \%$ ) valued cure but were indifferent to solvency and the smallest class (with $9 \%$ membership probability) valued solvency but were indifferent to cure. Two classes valued cure more than solvency by factors of 4.7 and 2.1 (with membership probabilities of 28 and $21 \%$, respectively). The final class preferred solvency to cure by a factor of 1.9 but illogically preferred either cure or solvency alone to cure and solvency together (membership probability $=11 \%$ ).

If willingness to pay for non-marginal risk reductions implied by the standard model is too large, what is the error in the model? One possibility is that the income elasticity of VSL increases sharply as the individual pays for increasing risk reductions. This might be explained by the phenomenon of mental accounting, in which individuals implicitly allocate their spending to different compartments and are reluctant to reallocate between them (Thaler 1985). Beattie et al. (1998) suggested that many survey respondents' willingness to pay is based not on the magnitude of the risk reduction (which is difficult to evaluate) but on an amount that "would not seriously disrupt their normal expenditure and savings patterns" (p. 20). As an example, if individuals allocate a fraction $\pi<1$ of their income to spending on mortality risk (or health and safety in general), then they will pay no more than that fraction of income for risk reduction. In this case, the elasticity of VSL with respect to the amount of income available for spending on risk reduction will be $1 / \pi$ times as large as the income elasticity that is conventionally estimated. If $\pi=20 \%$, an individual will not spend more than $20 \%$ of income on even a large risk reduction and the income elasticity of VSL with respect to this limited share is five times as large as conventionally estimated.

An alternative interpretation of these results is that there is no error; the value of survival is so large that individuals will exhaust their resources to purchase risk reductions on the order of $1 / 10$ or $1 / 100$. Even though the gain in expected utility is proportional to the risk reduction, they are unable to pay much more for additional risk reductions; hence both the average and marginal rates of substitution of wealth for survival probability fall sharply once the individual's budget is nearly exhausted. If the marginal utility of a bequest is near zero, the utility of wealth is nothing without survival. 
In summary, while it seems plausible many individuals could pay for survivalprobability increases on the order of 1 in 10,000 or less at a rate consistent with conventional estimates of VSL of about $\$ 10$ million, the standard model underlying VSL combined with empirical estimates of income elasticity implies that the average rate of substitution of wealth for survival probability declines sufficiently slowly as the risk reduction increases that individuals are predicted to be willing to pay more than half their income to reduce current-year mortality risk by 1 in 100 . If survival probability is much smaller than one, VSL and the compensating surplus for a risk reduction are even larger. For larger risk reductions, ability to pay is severely limited, hence the average value per unit risk reduction is much smaller than VSL. For a onetime risk reduction, individuals could spend from their wealth as well as from income, but for a continuing risk reduction payment would be effectively limited to income, because most households have little wealth compared with their incomes.

In the context of the COVID-19 pandemic, population mortality rates as of May 2020 have exceeded 1/2000 in some countries (e.g., Italy, Spain) and 1/500 in some regions (e.g., New York City); rates among the elderly are higher. The early estimate of 2.2 million deaths in the U.S. absent an effective response represents an average rate of $7 / 1000$ or $2 / 100$ if concentrated among the roughly 100 million U.S. residents aged 65 and above. These rates suggest that effective policies might achieve risk reductions on the order of 1/1000 or larger, for which the smaller rates of valuation for non-marginal risk reductions become important. The concentration of risk on identified subpopulations decreases the social value (the sum of individuals' willingness to pay) of any fixed reduction in the expected number of deaths in a population (Hammitt and Treich 2007).

\section{Valuing mortality risk by age}

It seems intuitive that the value of reducing current mortality risk is smaller for older than younger individuals, as the older have fewer years of life to protect. This notion is reinforced by the view that lifesaving is more valuable among younger cohorts that have not yet lived their "fair innings" (Harris 1985; Adler et al. 2019). However, VSL may increase or decrease with age in the standard model.

The expected utility gain from surviving the current period (the numerator of Eq. (2)) is the difference in utility between surviving and dying. The utility conditional on surviving, $u_{a}(w)$, depends on the multivariate lottery on longevity, health, income, and other factors the individual faces if she survives (it can be interpreted as the expected utility of this future lottery). Typically, it is reasonable to suppose the utility conditional on survival is increasing in life expectancy and hence tends to decrease with age. The effect of age on the utility of a bequest, $u_{d}(w)$, has received little attention in the literature. A common assumption is the marginal utility of the bequest is zero. It seems plausible the utility of a bequest could be larger for an individual whose children or spouse are dependent on her earnings, and hence might be larger during middle age than when younger or older; these concerns motivate the purchase of life insurance and could also increase $u_{a}(w)$ during periods when others are more dependent on the individual. The difference in utility between survival and death need not follow any 
simple pattern as a function of age but it seems plausible that it decreases with age, at least beyond some point.

The expected opportunity cost of spending, the denominator of Eq. (2), may also depend on age, though the direction of the effect is uncertain. Two considerations suggest the expected opportunity cost of spending may decrease with age. First, because current-period survival probability decreases with age, the expected opportunity cost will decrease via the dead-anyway effect. Second, for an individual supporting herself from existing wealth with little or no future income, the marginal utility of wealth conditional on survival, $u_{a}{ }^{\prime}(w)$, will tend to increase with life expectancy as she must be prepared to support herself over a longer period; a shorter life expectancy will decrease the marginal utility. For an individual with continuing income such as a pension or annuity, this effect would be smaller and perhaps reversed if her income exceeds her expenses. The change in VSL with age depends on the rates at which both the numerator and denominator change. If the expected opportunity cost of spending decreases sufficiently rapidly with age, it can offset a decrease in the utility gain from survival and hence VSL may increase with age. If not, VSL will tend to decrease with age.

Further insight into the pattern of VSL with age requires imposing more structure. The usual approach is to assume lifetime utility is additively separable across periods, utility conditional on survival is the expected present value of future utility of consumption, and the marginal utility of a bequest is zero (e.g., Shepard and Zeckhauser 1984; Rosen 1988; Cropper and Sussman 1990; Ng 1992), yielding

$$
U_{a}=\sum_{t=a}^{T} \rho^{t-a} s_{a}(t) u[c(t)]
$$

where $a$ is the individual's age, $T$ is an upper bound on attainable age, $\rho$ is her utility discount factor, $s_{a}(t)$ is her probability of surviving from age $a$ to age $t, u[c(t)]$ is her utility of consumption $c$ at age $t$, and utility conditional on death is normalized to zero. The individual is assumed to maximize expected utility (8) subject to a budget constraint such as

$$
\sum_{t=a}^{T} r^{t-a} s_{\mathrm{a}}(t) c(t)=w(a)+\sum_{t=a}^{T} r^{t-a} s_{a}(t) y(t)
$$

where $r$ is the market discount factor, $w(a)$ is her wealth at age $a$, and $y(t)$ is her income at age $t$. Model results depend on assumptions about whether the individual can borrow against future income (as in Eq. (9)) and on the relationship between her utility discount factor and the market discount factor. If the individual can borrow against future income and the discount factors are equal, it is optimal to equalize consumption in all periods and VSL is proportional to the expected present value of longevity. If the individual can save but not borrow against future income, VSL tends to rise over younger ages (when income is low) and fall over older ages, tracing a so-called inverted U. If the utility discount factor is larger than the market discount factor (i.e., the individual discounts future utility at a rate smaller than the interest rate), VSL also follows an inverted $U$ even if the individual can borrow against future income; in this case, it is optimal to defer consumption from younger to older ages and the opportunity cost of spending decreases with age. 
Table 2 reports estimates of the ratio of VSL at age 75 to VSL at age 40 from illustrative studies. The first panel reports results of lifecycle models. All of the identified studies find that VSL is substantially larger at age 40 than at age 70 , by a factor of between two and more than ten.

Empirical estimates of VSL as a function of age yield diverse results but tend to suggest a flatter profile. Estimates from studies of compensating wage differentials for occupational fatality risk are limited to working-age adults and must account for differences in occupational fatality risk by age. As reported in the second panel of Table 2, Aldy and Viscusi (2008) and Aldy (2019) estimated VSL at age 40 is roughly one to two times as large as at ages near 60.

Stated-preference studies are not limited to working-age populations and many have reported estimates of how VSL varies with age. One of the first, Jones-Lee et al. (1985), estimated VSL as a quadratic function of age; the U.S. Environmental Protection Agency used a regression model from this study to inform its assumption that VSL is $37 \%$ smaller above age 65 than below (the so-called senior death discount; Robinson 2007, Viscusi 2009), implying a ratio of VSL at age 40 to VSL at age 75 of 1.6. Cameron and DeShazo (2013) estimated that VSL is highly sensitive to age, peaking at $\$ 8$ million near age 55 and smaller than $\$ 2$ million at ages younger than 35 and older

Table 2 Selected estimates of VSL at age 40 relative to VSL at age 75

\section{VSL(40) / VSL (75) Comments}

\begin{tabular}{|c|c|c|}
\hline \multicolumn{3}{|l|}{ Simulation models } \\
\hline $\begin{array}{l}\text { Shepard and Zeckhauser } \\
\text { (1984) }\end{array}$ & $3.3,12.5$ & Can or cannot borrow against future earnings \\
\hline Smith and Keeney (2005) & 6.0 & \\
\hline Murphy and Topel (2006) & 4.0 & \\
\hline Aldy and Smyth (2014) & 1.9 & \\
\hline Adler et al. (2019) & $3.1,5.3,6.4,5.1,3.8$ & By income quintile (lowest to highest) \\
\hline \multicolumn{3}{|c|}{ Compensating wage-differentials } \\
\hline Aldy and Viscusi (2008) & $\begin{array}{l}1.5 ; \operatorname{VSL}(40) / \\
\operatorname{VSL}(62)\end{array}$ & Adjusted for increasing lifetime earnings by cohort \\
\hline Aldy (2019) & $\begin{array}{l}0.9,1.6,2.1 \\
\operatorname{VSL}(35-44) / \\
\operatorname{VSL}(55-62)\end{array}$ & Results from alternative regression models \\
\hline \multicolumn{3}{|l|}{ Stated preference } \\
\hline Jones-Lee et al. (1985) & 1.6 & Calculated from regression, used by U.S. EPA \\
\hline Johannesson et al. (1997) & 1.5 & \\
\hline Alberini et al. (2004) & 1.3 & \\
\hline $\begin{array}{l}\text { Cameron and DeShazo } \\
\text { (2013) }\end{array}$ & 2.2 & Fig. 1 \\
\hline Krupnick (2007) & $1.3-1.5$ & $\begin{array}{l}14 \text { of } 26 \text { estimates reviewed show smaller VSL at older } \\
\text { ages, clustering around } 20-35 \% \text { smaller at age } 70 \text { than } \\
\text { age } 40\end{array}$ \\
\hline
\end{tabular}


than 75 (their Fig. 1). In his review, Krupnick (2007) identified 26 stated-preference studies that satisfy selected indicators of study quality. Of these, 14 showed a statistically significantly smaller VSL at age 65 and older compared with younger ages; the other 12 showed no significant effect or a larger VSL at older ages. Of the studies finding a smaller VSL at older ages, the estimated magnitude clustered around a reduction of 20 to $35 \%$, implying a ratio of 1.3 to 1.5 .

VSL characterizes the value of increasing survival probability for a specified short period. If the mortality risk from SARS-CoV-2 were anticipated to virtually disappear in a year or two, because of widespread availability of an effective vaccine or treatment, the development of herd immunity, or other reasons, the benefits of actions to reduce transmission could be calculated as the value of a short-term risk reduction. Alternatively, if the risk were anticipated to persist, the benefits of control would continue to manifest over a longer period. In this case, developing and administering an effective vaccine could produce annual benefits that persist for many years.

The value to an individual of a persistent change in mortality risk equals the expected present value of a stream of benefits. For an individual of age $a$, the value of a stream of risk reductions $\delta(t)$ is given by

$$
V_{a}=\sum_{t=a}^{T} r^{t-a} s_{a}(t) v(t) \delta(t)
$$

where $v(t)$ is the individual's average rate of substitution of wealth for a risk reduction $\delta(t)$ at age $t$ (i.e., her VSL at age $t$ if $\delta(t)$ is sufficiently small). Hence, even if VSL does not decrease with age, the value of a continuing risk reduction may be smaller to an older than to a younger person because of her shorter life expectancy. If $v(t)$ is independent of age, the value of a constant annual risk reduction $\delta(t)=\delta$ is proportional to the expected present value of longevity $\sum_{t=a}^{T} r^{t-a} s_{a}(t)$. With an interest rate of zero, the value is proportional to life expectancy. Under these assumptions, the value of a constant annual risk reduction to a 40 year old is more than three times as large as the value to a 75 year old (average U.S. life expectancies at ages 40 and 75 are 40.7 and 12.3 years, respectively; Arias and $\mathrm{Xu}$ 2019). Comparing life expectancies at ages 40 and 90 yields a ratio of nine (life expectancy at age 90 equals 4.5 years). These ratios are smaller using a positive interest rate and decrease toward one in the limit as the interest rate increases.

This effect of age on the relative value of a continuing risk reduction is attenuated if the risk reduction rises with age and can be reversed if it rises sufficiently rapidly and the interest rate is large enough. For example, if the risk reduction is a constant fraction of annual mortality risk it will rise sharply with age. The value of a continuing risk reduction that is proportional to age-specific mortality hazard to a 40 year old is 1.4 and 3.9 times as large as the value to a 75 and 90 year old, respectively, almost half as large as the corresponding ratio of life expectancies (using an interest rate of zero). Using a $3 \%$ interest rate, the relative values decrease to 0.6 and 1.4 , respectively, i.e., the value is larger for a 75 year old than for a 40 year old, which is larger than for a 90 year old.

In summary, while it is plausible that VSL is smaller at older than at middle ages, neither standard models nor empirical evidence provide strong evidence about the 
magnitude of the effect. Nevertheless, even if VSL does not vary much with age, the value of a persistent risk reduction may be smaller at older ages because the individual is likely to benefit for fewer years. For a persistent constant risk reduction and interest rate equal to zero, the value is proportional to life expectancy; the values are more uniform if the interest rate is larger. If the risk reduction increases with age and the interest rate is positive, the value of a continuing risk reduction can be larger to an older than a younger person. Whether the difference between the value of a short-term or a persistent risk reduction is important in the context of evaluating responses to the COVID-19 pandemic depends on the likelihood that the threat would be substantially eliminated in the absence of the responses being evaluated.

\section{Effects of lost income}

The pandemic and lockdown policies to respond to it have led to large income losses for workers and business owners in restaurants, travel, and other sectors. Because VSL is increasing with income, the appropriate VSL for evaluating responses to COVID-19 and other current hazards may be smaller than the value that was appropriate before the pandemic. ${ }^{5}$ This inference is correct, but the effect of a reduction in current income on the appropriate VSL may be much smaller than implied by the one-period model and estimates of the income elasticity of VSL presented in Section 2. The key issue is whether the current income loss is transient or expected to persist for an extended period. If the income loss is confined to the short term, the associated decrease in VSL is likely to be modest; in contrast, if the decrease in income is likely to persist through an extended economic recession, the decrease in the appropriate VSL will be larger.

Consider a simple two-period model, in which utility in each period is a function of consumption. For simplicity, assume that consumption is equal to income, the individual cannot borrow against future income, and the interest rate is zero. Let

$$
U=s\left[u\left(c_{1}\right)+t u\left(c_{2}\right)\right]
$$

where $u\left(c_{1}\right)$ is the utility of consuming at the rate $c_{1}$ in period 1 and $t u\left(c_{2}\right)$ is the utility of consuming at the rate $c_{2}$ in the second period. The probability of surviving the first period is $s$ and $t$ represents life expectancy conditional on surviving the first period; for most individuals, $t$ is much larger than one. The second term $t u\left(c_{2}\right)$ equals the expected present value of the utility of consumption conditional on surviving the first period, i.e., the summation in Eq. (8) excluding its first term. Assume the utility of a bequest is zero and that $u>0, u^{\prime}>0$, and $u^{\prime \prime} \leq 0$ as usual.

Absent the pandemic, the marginal rate of substitution of first-period consumption for first-period survival is

$$
V S L_{0}=-\frac{d c_{1}}{d s}=\frac{u\left(c_{1}\right)+t u\left(c_{2}\right)}{s u^{\prime}\left(c_{1}\right)} .
$$

\footnotetext{
${ }^{5}$ Guo and Hammitt (2009) found that VSL in China estimated using compensating wage differentials was substantially smaller when unemployment was high, providing empirical support for this claim.
} 
If income and consumption decrease by an amount $\Delta>0$ in the first period but will return to baseline in the second period, the marginal rate of substitution of first-period consumption for first-period survival becomes

$$
V S L_{1}=-\frac{d c_{1}}{d s}=\frac{u\left(c_{1}-\Delta\right)+t u\left(c_{2}\right)}{s u^{\prime}\left(c_{1}-\Delta\right)} .
$$

$V S L_{1}$ is smaller than $V S L_{0}$ : the numerator is smaller and the denominator is larger or equal. If the loss of income is anticipated to persist through the second period, the marginal rate of substitution of first-period consumption for first-period survival becomes

$$
V S L_{2}=-\frac{d c_{1}}{d s}=\frac{u\left(c_{1}-\Delta\right)+t u\left(c_{2}-\Delta\right)}{s u^{\prime}\left(c_{1}-\Delta\right)} .
$$

$V S L_{2}$ is smaller than $V S L_{1}$ : the numerator is smaller ${ }^{6}$ and the denominator is the same.

When the rates of consumption in the two periods are equal, $c_{1}=c_{2}=c$, the income elasticity as conventionally measured characterizes the change from $V S L_{0}$ to $V S L_{2}$. That is, $V S L_{2}=\left(\frac{c-\Delta}{c}\right)^{\gamma_{2}} V S L_{0}$, where the income elasticity (evaluated at $\Delta=0$ ) is

$$
\gamma_{2}=\frac{d V S L_{2}}{d c} \frac{c}{V S L_{2}}=-c \frac{u^{\prime \prime}(c)}{u^{\prime}(c)}+c \frac{u^{\prime}(c)}{u(c)} .
$$

Note that the income elasticity is the sum of two terms, the Arrow-Pratt measure of relative risk aversion and the measure of relative boldness ${ }^{7}$ (Eeckhoudt and Hammitt 2001). The first term is non-negative and the second is strictly positive.

In contrast, the elasticity of $V S L_{1}$ with respect to a transient decrease in first-period consumption (evaluated at $\Delta=0$ ) is

$$
\gamma_{1}=\frac{d V S L_{1}}{d c_{1}} \frac{c_{1}}{V S L_{1}}=-c_{1} \frac{u^{\prime \prime}\left(c_{1}\right)}{u^{\prime}\left(c_{1}\right)}+c_{1} \frac{u^{\prime}\left(c_{1}\right)}{u\left(c_{1}\right)+t u\left(c_{2}\right)} .
$$

When the rate of consumption is equal in the two periods, $\gamma_{1}$ is smaller than $\gamma_{2}$ because the denominator of the last term in Eq. (16) is larger than the corresponding term in Eq. (15). Hence adjusting VSL using a conventional estimate of its income elasticity is correct if the income loss is permanent but overestimates the decrease in VSL if the income loss is temporary.

If the income loss is temporary, $V S L_{1}$ characterizes the individual's rate of substitution of current consumption for survival but it is not necessarily the appropriate measure for evaluating public policies that reduce mortality risk. Even if the individual cannot borrow against future income to prevent a reduction in current consumption, governments can and are supporting current consumption through deficit spending

\footnotetext{
${ }^{6}$ Compared with $\mathrm{VSL}_{0}$, the decrease in the numerator associated with $\mathrm{VSL}_{2}$ is $(1+t)$ times as large as the decrease associated with $\mathrm{VSL}_{1}$ (when $c_{I}=c_{2}$ ).

${ }^{7}$ Boldness measures an individual's willingness to accept a monetary gamble offering a small gain at the risk of a small probability of ruin (Aumann and Kurz 1977).
} 
supported by public borrowing. Through this mechanism, government can shift the opportunity cost of measures to reduce mortality risk from the first to the second period.

Shifting the costs of policies to increase first-period survival to the second period reduces the opportunity cost by spreading the consumption loss over a longer period. That is, if $\Delta$ is the cost and $c_{2} \geq c_{1}$, then the concavity of $u$ implies $t\left[u\left(c_{2}\right)-u\left(c_{2}-\frac{\Delta}{t}\right)\right]$ $\leq u\left(c_{1}\right)-u\left(c_{1}-\Delta\right)$, with strict inequality if $u^{\prime \prime}<0$.

As noted above, VSL is sensitive to other factors that affect second-period wellbeing in addition to income. For example, second period utility is larger if the probability of developing an effective vaccine or treatment is larger; this could improve utility directly (due to reduced fear and anxiety) and increase life expectancy conditional on surviving the first period.

In summary, although the lost income associated with the pandemic and response policies decreases current VSL, its effect on the appropriate VSL for evaluating policies may be much smaller than a simple adjustment of VSL based on existing estimates of the income elasticity would imply. The correct VSL is more sensitive to long-run income than to a transient reduction due to the pandemic. If economic recovery is anticipated to be rapid, there might be little effect on the appropriate VSL, but if the income loss is sustained, the effect on VSL will be larger. Moreover, the burden of lost consumption is smaller if it is spread over a longer period through government borrowing.

\section{Psychological factors and valuation}

Risk-perception studies have revealed that people's concerns about different sources of health risk and preferences for controlling them depend on a number of qualitative factors in addition to the probabilities and severities of possible harms. This concept can be summarized as "risk as feelings" (Loewenstein et al. 2001). The degree to which a risk is characterized by a risk-perception factor is not objective but a characteristic of the observer. The influence of these qualitative risk-perception factors is related to the two-system model of judgment and decision making in which one system is fast, automatic, and sensitive to psychological affect while the other is slower, effortful, and deliberative (Slovic et al. 2004; Kahneman 2011).

Key risk-perception factors have been condensed using factor analysis into two dimensions: dread and uncertainty (Fischhoff et al. 1978; Slovic et al. 1984; Slovic 1987). ${ }^{8}$ Dread risks are judged to be uncontrollable, involuntary, potentially catastrophic, increasing over time, fatal, or inequitably distributed. Uncertain risks are judged to be new, unobservable, not known to those who are exposed, having delayed effects, or unknown to science. Clearly, in the early days of the pandemic COVID-19 has many of these attributes and it is reasonable to suppose that it has been viewed as a greater risk than consideration of only the probability and severity of illness alone would suggest.

Another psychological factor that can affect judgments about the severity of a risk and appropriate control measures is ambiguity aversion (Trautmann and van de Kuilen 2015). Research dating to Ellsberg (1961) has found that individuals are averse to

\footnotetext{
${ }^{8}$ Margolis (1996) criticized this paradigm, suggesting that judgments about risk are primarily determined by perceptions of compensating benefits.
} 
ambiguity, defined as a situation in which the probabilities of possible outcomes are unknown or poorly estimated. Ambiguity aversion describes a preference for lotteries with clearly known probabilities over those where the probabilities are less clear; risks posed by a novel virus or other newly emerging threat are invariably ambiguous. Ambiguity aversion seems closely related to the risk-perception factor "uncertainty" but the two concepts have been investigated in different research traditions (psychology and decision theory, respectively) and have not been well-integrated.

While it is clear that risk-perception factors and ambiguity aversion may be associated with increased concern about COVID-19 risks, the extent to which these factors support using a larger VSL for COVID-19 than for other fatal risks is uncertain. Theoretical models of the effects of ambiguity aversion on choices have been developed but models for other risk-perception factors have not. Limited empirical evidence about both ambiguity and other risk-perception factors is available from statedpreference studies.

Treich (2010) showed that VSL is larger for an ambiguous risk than for an unambiguous risk, and that the difference increases with both the individual's degree of ambiguity aversion and the ambiguity of the risk. Adapting Eq. (2) using the Klibanoff et al. (2005) smooth model of ambiguity aversion, he showed that ambiguity aversion, by putting more weight on larger fatality probabilities, is similar to the deadanyway effect by which VSL increases with baseline risk. This similarity implies that the effect of ambiguity aversion on VSL may be modest. But in cases where ambiguity is so great that mortality probabilities approaching one are contemplated, the effect on VSL could be large, especially under alternative models of ambiguity aversion (e.g., Gilboa and Schmeidler 1989; Gajdos et al. 2008) that put substantial weight on the most pessimistic probabilities. Note these results apply to the case where the baseline risk is ambiguous but the risk reduction is not; ambiguity aversion need not increase willingness to pay for a protective action when its efficacy is ambiguous (Treich 2010). Bleichrodt et al. (2019) extended this work to show that VSL for a more ambiguous risk is not necessarily larger than for a less ambiguous risk; the difference depends on higher-order moments of the ambiguity and of the individual's preferences.

Only a few studies have estimated the effect of ambiguity on the value of reducing health risks. Viscusi et al. (1991) presented survey respondents with a case in which the chance of developing nonfatal nerve disease due to environmental pollution if living in one town was ambiguous (equal to either of two values) and elicited the single probability of disease if living in a different town such that the respondent was indifferent to living in either town. For an ambiguous risk equal to either 150 or 200 in 1 million, the mean single probability equivalent was 178 in 1 million; for an ambiguous risk equal to either 110 or 240 in 1 million, the mean single probability equivalent was 191 in 1 million. To interpret these results, consider the ratio of the ambiguity premium (the difference between the single probability and the mean of the two probabilities, 175 in 1 million) and the degree of ambiguity (the absolute difference between each possible risk and their mean). For the less ambiguous risk, the ambiguity premium is 3 and the degree of ambiguity is 25 , a ratio of roughly one-eighth; for the more ambiguous risk, the ambiguity premium is 16 and the degree of ambiguity is 65 , a ratio of roughly one-quarter; this suggests the ambiguity premium is more than proportional to the degree of ambiguity. 
Shogren (2005) reported a study in which willingness to pay was elicited to reduce the chance of salmonella poisoning when eating at a restaurant. Some respondents were told the probability of illness ( 1 in 10,1 in $100, \ldots$, or 1 in 10 million); others were told the two food inspectors disagreed and their estimates were 0.5 and 1.5 in 10, 0.5 and 1.5 in $100, \ldots$, or 0.5 and 1.5 in 10 million. For six of the seven risk levels, mean willingness to pay to eliminate the risk was between 1.1 and 2.0 times larger when the two alternative probabilities were given rather than the single probability (it was four times larger for the case with a single probability of 1 in 10 million), though the difference in willingness to pay between ambiguous and sharp probabilities was not statistically significant. The limited sensitivity of mean willingness to pay to the risk reduction casts doubt on the validity of these estimates; it decreased from $\$ 49$ for the 1 in 10 risk to $\$ 13$ for the 1 in 10 million risk.

Riddel and Shaw (2006) elicited perceived mortality risk and willingness to accept monetary compensation for the risk from residents near a hypothetical railroad line transporting nuclear waste. Respondents were asked to report the risk they would confront as a point or range. Respondents whose risk estimates spanned a larger range demanded higher compensation. The reported regression model implies that willingness to accept compensation for an ambiguous risk (between 0 and $2 p$ ) is about 1.8 times as large as willingness to accept compensation for an unambiguous risk of $p .{ }^{9}$

The relationships between other risk-perception factors and VSL have been examined in a number of stated-preference studies. Studies comparing VSL associated with fatal cancers and with traffic fatalities, other chronic disease, or other hazards suggest the value of cancer risk is larger by a factor of between one and three (McDonald et al. 2016). Chilton et al. (2006) elicited focus-group participants' judgments of dread and relative values of risk reduction for murder and a range of fatal accidents (including inhome, pedestrian, motor-vehicle, rail, fire in a public place, drowning); they found a strong correlation between dread and the value of risk reduction, which spans a factor of five. Subramanian and Cropper (2000) elicited judgments of the number of fatalities from different hazards that were judged to be equivalent, finding differences of a factor of about two or less. The differences were associated with judgments of controllability and voluntariness. Jones-Lee and Loomes (1995) estimated that respondents valued a reduction in fatalities in subway accidents 1.5 times as much as fatalities in road accidents. This difference is associated with differences in the perceived involuntary and uncontrollable nature, but not the catastrophic potential, of subway accidents. Comparing preferences for reducing risks of rail and traffic fatalities before and after a major rail accident, Chilton et al. (2002) found that perceived risks of rail accidents had increased but the relative value of reducing rail rather than traffic risks increased only $20 \%$.

Catastrophic risks entail a clustering of deaths in time, space, or from a common cause such as a pandemic. Rheinberger and Treich (2017) defined one risk as more catastrophic than a second if the probability distribution of the number of deaths (or other adverse outcome) for the first risk is second-order stochastically dominated by the distribution for the second risk. If the expected numbers of deaths are equal, one risk is more catastrophic than another if its distribution is a mean-preserving spread of the

\footnotetext{
${ }^{9}$ This result is calculated by dividing twice the coefficient for ambiguity $(2 \mathrm{x}-0.3)$ by the coefficient for risk $(-0.8)$ from Table 2 of Riddel and Shaw (2006).
} 
distribution for the other risk (this definition parallels the Rothshchild and Stiglitz (1970) definition of risk).

For risks having the same expected number of deaths, one can be more catastrophic than another if individuals' risks are positively correlated or if they are more equal. Mortality risks from COVID-19 are positively correlated because they depend on how effectively the spread of infection is controlled. In the standard model (Eq. (2)), VSL is an individual's rate of substitution of wealth for survival probability and is unaffected by correlation of her risk with others. If so, VSL is insensitive to this source of catastrophic risk. However, the utility of survival may depend on whether other people survive or die; if the individual's utility of survival is diminished when others die, VSL will be larger when individual risks are positively correlated than when they are independent or negatively correlated. Hence VSL may be increased by this source of catastrophic risk through common-fate preference (Schelling 1968). The concentration of mortality risk on the elderly and other subpopulations makes the pandemic risk less catastrophic than it would be if the risks were distributed more equally. This concentration decreases the total social value of risk reduction (Hammitt and Treich 2007), implying the value would be larger if the risk were more catastrophic because individual risks were more equal.

Rheinberger and Treich reviewed 19 empirical studies of preferences between alternative risks to lives and found that the more catastrophic risk was almost always preferred; this suggests that willingness to pay and the associated VSL are smaller, not larger, for a more catastrophic risk. Both common-fate preference and a preference for more equally distributed risks (Keeney 1980; Bernard et al. 2018) may explain this result; another possibility is risk seeking preferences in the domain of losses (Kahneman and Tversky 1979).

In a study that provides perhaps the closest parallel to the COVID-19 pandemic, Liu et al. (2005) estimated VSL to reduce risk of SARS in Taiwan, a country that was strongly affected by that epidemic. Stated-preference data were collected (mostly by telephone) between mid-April and late May 2003 during the height of the epidemic. Approximately 1500 respondents were asked about their knowledge and perceptions of SARS risk and their willingness to pay for a hypothetical vaccine that would eliminate the risk of infection. Respondents reported they were knowledgeable about SARS and judged it to be moderately controllable. The risk reduction valued was marginal: Respondents were told the infection risk was either 3 or 5 per 100,000 per month, the conditional fatality risk was 0.05 or 0.10 , and the vaccine would be effective for 3 , 6 , or 12 months. Willingness to pay was statistically significantly associated with the randomly assigned magnitude and duration of risk reduction, though less than proportional so estimates of VSL are larger for the smaller risk reductions and shorter durations.

Estimated VSL ranges between \$3 and \$12 million (U.S. dollars). These values are substantially larger than values previously estimated for Taiwan. For example, Hammitt and Liu (2004) conducted a stated-preference study in which they elicited willingness to pay to reduce risk of developing a fatal cancer or other disease through air pollution (lung disease) or drinking water (liver disease) that would lead to death within two to three years. Using data collected in May 2001 (two years before the SARS outbreak), they estimated VSL for fatal lung cancer as \$2.1 to 2.2 million and VSL for other fatal lung disease as $\$ 1.5$ to 1.6 million. (Estimates for fatal liver disease 
or liver cancer were substantially smaller, $\$ 0.7$ to $\$ 1.1$ million.) The estimates of VSL for SARS are roughly 1.5 to 6 times larger than those for fatal lung disease or cancer from air pollution.

In the context of a World Health Organization warning that an influenza epidemic was imminent, Gyrd-Hansen et al. (2008) surveyed a sample of Norwegian adults about their perceptions of the number of deaths that would occur if a serious influenza epidemic were to occur in Norway, the number that would be prevented if Tamiflu were stockpiled and made widely available, and their willingness to pay to have Tamiflu available for themselves. They estimated mean and median VSL of $\$ 9.7$ and $\$ 1.5$ million (U.S. dollars). Respondents who reported they were likely to take strong personal precautions (interpreted as a measure of anxiety) had higher willingness to pay and estimated the risk to be larger; those who reported high trust in the government had lower willingness to pay and estimated the risk to be smaller.

In summary, the risk-perception literature finds that concerns about health risks are associated with qualitative factors such as dread, uncertainty, and ambiguity, in addition to the probabilities and severities of harms. The COVID-19 pandemic displays many of the characteristics that are associated with high perceived risk. Studies of the relationship between risk-perception factors and the value of risk reduction yield conflicting results but suggest that monetary values may be substantially larger for more feared risks, perhaps by a factor of two or more. Comparing results from a study conducted during the SARS epidemic with a previous study suggests the contemporaneous value of reducing fatality risk from a coronavirus epidemic may be at least twice as large as for ubiquitous risks such as lung disease or cancer from air pollution. A key question is whether a higher value of risk reduction elicited during a pandemic is an informed and considered judgment that justifies a strong response or is an exaggerated and perhaps panicked response in the moment (Robinson and Hammitt 2011; Hammitt 2013; Shogren and Thunström 2016).

\section{Conclusion}

A key parameter in evaluating policies that respond to the COVID-19 pandemic is the tradeoff between mortality risk and wealth, typically characterized as the value per statistical life (VSL). For the U.S., current estimates of VSL used by the federal government are approximately $\$ 10$ million; at rates like this, policies to reduce projected fatalities from COVID-19 can be worth trillions of dollars (e.g., Greenstone and Nigam 2020; Thunström et al. 2020; Hall et al. 2020).

Is a VSL of $\$ 10$ million appropriate for this evaluation? There are at least three reasons to think it is too large, but other reasons to think it is not. First, VSL is defined as an individual's marginal rate of substitution between wealth and probability of surviving the current period (typically a short period such as a year). Clearly, few could pay at this rate for a non-marginal risk reduction, and the risks associated with COVID-19 appear non-marginal. ${ }^{10}$ The standard model underlying VSL implies that

\footnotetext{
${ }^{10}$ Although the fatality risk from the pandemic may be non-marginal, the risk changes associated with many specific policy decisions, such as opening schools or certain classes of business, may be marginal.
} 
the average rate of substitution between wealth and survival probability is a decreasing function of the increment to survival probability. The rate of decrease is tied to the wealth elasticity of VSL. Estimates of this elasticity imply that the average rate of willingness to pay for risk reduction decreases sufficiently slowly as the risk reduction increases that individuals will virtually exhaust their wealth to increase the probability of surviving a year by as little as 0.1 or less. The average rates at which larger risk reductions are valued necessarily decrease rapidly with the risk reduction. The plausibility of these results may be questioned. Reconciling theory, empirical estimates, and the plausibility of willingness to pay for non-marginal risk reductions is an important research topic.

Second, COVID-19 mortality risk seems to be concentrated among the elderly and it is plausible that VSL is smaller at advanced ages. Because VSL is a rate of substitution between wealth and survival probability, the one-period model does not imply that it decreases with age. The conventional life-cycle model that assumes lifetime utility is additively separable across periods suggests VSL declines with age after some point, though the age at which it begins to decrease and the rate of decrease are sensitive to parameter values. Empirical estimates of whether and how much VSL decreases at older ages conflict; a judgmental summary suggests a modest decrease at advanced ages. If SARS-CoV-2 is anticipated to be a persistent rather than a transient threat, the relative value of controlling it for older versus younger individuals will be suppressed, independent of any age-related difference in VSL, because the old will benefit from a continuing risk reduction for a shorter period.

Third, the COVID-19 pandemic and responses to it have led to large income losses, especially in certain sectors. Because VSL is increasing in income, this implies VSL has decreased. But VSL depends on future as well as current income; the effect of income loss on the appropriate value for evaluating response policies is sensitive to whether the income loss is expected to persist. If income loss is transient, the effect on the appropriate VSL should be modest. Analogously, expectations about other future conditions affect VSL; a larger probability or shorter expected arrival time for an effective vaccine or treatment increases VSL.

Other considerations suggest the appropriate VSL for evaluating responses to COVID-19 may be larger than $\$ 10$ million. VSL depends on individuals' preferences and if they prefer to reduce risks that are judged to be more dreaded, uncertain, and ambiguous than other fatal risks (as COVID-19 may be), a larger VSL is warranted. The literature on how large an adjustment is appropriate is limited and conflicting: some evidence suggests no adjustment is needed while other evidence suggests increasing VSL by a factor of two or more could be supported. Whether it is appropriate to adjust VSL in response to risk-perception characteristics and ambiguity depends on whether judgments about these attributes are viewed as well-considered or rash.

Note that although the factors studied here have been discussed in the context of COVID-19, they apply more broadly. The valuation of non-marginal risk reductions is relevant to other mortality risks where large reductions are possible, such as in health care. The finding that the value of a continuing risk reduction is decreased for older relative to younger cohorts is relevant to regulation of environmental health risks and provides support for the intuition common in debates about air-pollution regulation that benefits are smaller for older individuals: even if their VSL is no smaller, they will 
expect to benefit for a shorter period. Economic recessions do not justify substantially weakening risk regulations, especially if they are anticipated to be short-lived. Finally, efforts to converge on a common VSL for evaluating policies toward different mortality risks may go too far if differences in risk-perception factors justify differences in valuation.

A critical issue in evaluating COVID-19 response policies is the likely difference between the population distributions of benefits and of costs. Mortality risks (and benefits of control) are concentrated among older cohorts and costs associated with social distancing and closure of workplaces and schools are born primarily by younger cohorts (Gollier 2020). Retirees suffer less directly from job loss than do people of working age. Benefit-cost analysis compares the monetary value of the benefits to those who gain from a policy with the monetary value of the costs to those who are harmed; even if the net social benefits of social distancing and other responses are positive, the net private costs to some people may be large. In the context of COVID-19 or other settings where the distribution of benefits is concentrated among the elderly, treating private benefits as social benefits may be less appropriate than in other contexts. VSL for elderly people is larger than it would otherwise be because their private opportunity costs of spending are low, due to their greater current-period mortality risk and shorter life expectancy. If an individual were spending her own wealth on risk reduction, using her private opportunity cost would be appropriate. But the low private opportunity cost to the elderly does not necessarily justify spending wealth (or reducing incomes) of younger people, whose private opportunity costs are larger. For evaluating policies that reduce mortality risk to different age groups, a utilitarian or even prioritarian social welfare function may provide better guidance (Adler 2019; Adler et al. 2019).

Acknowledgements I thank Matthew Adler, Richard Bradley, Daniel Herrera-Araujo, Stefan Pollinger, Arnaud Reynaud, Christoph Rheinberger, Lisa Robinson, Paul Seabright, Ryan Sullivan, Nicolas Treich, Kip Viscusi, Alex Voorhoeve, and participants at the Toulouse School of Economics COVID economics seminar for helpful comments. I acknowledge funding from the U.S. National Science Foundation (award number 1824492) and the French National Research Agency (ANR) under the Investments for the Future program (Investissements d'Avenir, grant ANR-17-EURE-0010).

\section{References}

Adler, M. D. (2019). Measuring social welfare: An introduction. Oxford: Oxford University Press.

Adler, M.D., Ferranna, M., Hammitt, J.K., \& Treich, N. (2019). Fair innings? The utilitarian and prioritarian value of risk reduction over a whole lifetime. Duke Law School Public Law \& Legal Theory Series no. 2019-79. Available at SSRN: https://ssrn.com/abstract=3493976.

Alberini, A., Cropper, M., Krupnick, A., \& Simon, N. B. (2004). Does the value of a statistical life vary with age and health status? Evidence from the US and Canada. Journal of Environmental Economics and Management, 48(1), 769-792.

Aldy, J.E., \& Smyth, S.J. (2014). Heterogeneity in the value of life. NBER working paper 20206.

Aldy, J. E., \& Viscusi, W. K. (2008). Adjusting the value of a statistical life for age and cohort effects. Review of Economics and Statistics, 90(3), 573-581.

Aldy, J. E. (2019). Birds of a feather: Estimating the value of statistical life from dual-earner families. Journal of Risk and Uncertainty, 58(2-3), 187-205.

Arias, E., \& Xu, J. (2019). United States Life Tables, 2017. National Vital Statistics Reports, 68(7), June 24.

Aumann, R. J., \& Kurz, M. (1977). Power and taxes. Econometrica, 45(5), 1137-1161. 
Bernard, C., Rheinberger, C. M., \& Treich, N. (2018). Catastrophe aversion and risk equity in an interdependent world. Management Science, 64(10), 4490-4504.

Barseghyan, L., Molinari, F., O’Donoghue, T., \& Teitelbaum, J. C. (2018). Estimating risk preferences in the field. Journal of Economic Literature, 56(2), 501-564.

Beattie, J., Covey, J., Dolan, P., Hopkins, L., Jones-Lee, M., Loomes, G., Pidgeon, N., Robinson, A., \& Spencer, A. (1998). On the contingent valuation of safety and the safety of contingent valuation: Part $1-$ Caveat investigator. Journal of Risk and Uncertainty, 17(1), 5-25.

Bleichrodt, H., Courbage, C., \& Rey, B. (2019). The value of a statistical life under changes in ambiguity. Journal of Risk and Uncertainty, 58(1), 1-15.

Broughel, J., \& Viscusi, W. K. (2020). The mortality cost of expenditures. Contemporary Economic Policy. https://doi.org/10.1111/coep.12483.

Cameron, T. A., \& DeShazo, J. R. (2013). Demand for health risk reductions. Journal of Environmental Economics and Management, 65(1), 87-109.

Cardoso, D.S., \& Dahis, R. (2020). Value of a statistical life under large mortality risk change: Theory and an application to COVID-19. https://ssrn.com/abstract=3599529.

Chapman, K. S., \& Hariharan, G. (1994). Controlling for causality in the link from income to mortality. Journal of Risk and Uncertainty, 8, 85-94.

Chapman, K. S., \& Hariharan, G. (1996). Do poor people have a stronger relationship between income and mortality than the rich? Implications of panel data for health-health analysis. Journal of Risk and Uncertainty, 12(1), 51-63.

Chilton, S., Covey, J., Hopkins, L., Jones-Lee, M., Loomes, G., Pidgeon, N., \& Spencer, A. (2002). Public perceptions of risk and preference-based values of safety. Journal of Risk and Uncertainty, 25(3), 211232.

Chilton, S., Jones-Lee, M., Kiraly, F., Metcalf, H., \& Pang, W. (2006). Dread risks. Journal of Risk and Uncertainty, 33(3), 165-182.

Corso, P. S., Hammitt, J. K., \& Graham, J. D. (2001). Valuing mortality-risk reduction: Using visual aids to improve the validity of contingent valuation. Journal of Risk and Uncertainty, 23(2), 165-184.

Costa, D. L., \& Kahn, M. E. (2004). Changes in the value of life, 1940-1980. Journal of Risk and Uncertainty, 29(159-180), 2004.

Cropper, M. L., \& Sussman, F. G. (1990). Valuing future risks to life. Journal of Environmental Economics and Management, 19(2), 160-174.

Drèze, J. (1962). L'utilitè sociale d'une vie humaine. Revue Française de Recherche Opèrationelle, 6, 93-118.

Eeckhoudt, L. R., \& Hammitt, J. K. (2001). Background risks and the value of a statistical life. Journal of Risk and Uncertainty, 23(3), 261-279.

Ellsberg, D. (1961). Risk, ambiguity, and the Savage axioms. Quarterly Journal of Economics, 75(4), 643669.

Evans, M. F., \& Smith, V. K. (2010). Measuring how risk tradeoffs adjust with income. Journal of Risk and Uncertainty, 40(1), 33-55.

Ferguson, N. M., et al. (2020). Impact of non-pharmaceutical interventions (NPIs) to reduce COVID-19 mortality and healthcare demand. Imperial College COVID-19 Response Team, London, (16 March 2020).

Fischhoff, B., Slovic, P., Lichtenstein, S., Read, S., \& Combs, B. (1978). How safe is safe enough? A psychometric study of attitudes toward technological risks and benefits. Policy Sciences, 9(2), 127-152.

Gajdos, T., Takashi, H., Tallon, J.-M., \& Vergnaud, J.-C. (2008). Attitude toward imprecise information. Journal of Economic Theory, 140(23-56), 2008.

Gilboa, I., \& Schmeidler, D. (1989). Maxmin expected utility with non-unique prior. Journal of Mathematical Economics, 18(2), 141-153.

Gollier, C. (2020). If the objective is herd immunity, on whom should it be built? COVID Economics, 16, 98114.

Greenstone, M., \& Nigam, V. (2020). Does social distancing matter? COVID Economics, 7, 1-23.

Guo, X., \& Hammitt, J. K. (2009). Compensating wage differentials with unemployment: Evidence from China. Environmental and Resource Economics, 42(2), 187-209.

Gyrd-Hansen, D., Halvorsen, P. A., \& Kristiansen, I. S. (2008). Willingness-to-pay for a statistical life in the times of a pandemic. Health Economics, 17(1), 55-66.

Hall, R. E., Jones, C. I., \& Klenow, P. J. (2020). Trading off consumption and COVID-19 deaths. Mimeo: Stanford University.

Hammitt, J. K. (2013). Positive vs. normative justifications for benefit-cost analysis: Implications for interpretation and policy. Review of Environmental Economics and Policy, 7(2), 199-218. 
Hammitt, J. K., \& Liu, J.-T. (2004). Effects of disease type and latency on the value of mortality risk. Journal of Risk and Uncertainty, 28(1), 73-95.

Hammitt, J. K., \& Haninger, K. (2010). Valuing fatal risks to children and adults: Effects of disease, latency, and risk aversion. Journal of Risk and Uncertainty, 40(1), 57-83.

Hammitt, J.K., \& Robinson, L.A. (2011). The income elasticity of the value per statistical life: Transferring estimates between high and low income populations. Journal of Benefit-Cost Analysis, 2(1), article 1, https://doi.org/10.2202/2152-2812.1009.

Hammitt, J. K., \& Treich, N. (2007). Statistical vs. identified lives in benefit-cost analysis. Journal of Risk and Uncertainty, 35(1), 45-66.

Hammitt, J. K., Geng, F., Guo, X., \& Nielsen, C. P. (2019). Valuing mortality risk in China: Comparing stated-preference estimates from 2005 and 2016. Journal of Risk and Uncertainty, 58(2-3), 167-186.

Harris, J. (1985). The value of life. London: Routledge and Kegan Paul.

Himmelstein, D., Thorne, D., Warren, E., \& Woolhandler, S. (2009). Medical bankruptcy in the United States, 2007: Results of a national study. American Journal of Medicine, 122(8), 741-746.

Hoffmann, S., Krupnick, A., \& Qin, P. (2017). Building a set of internationally comparable VSL studies: Estimates of Chinese willingness to pay to reduce mortality risk. Journal of Benefit-Cost Analysis, 8(2), 251-289.

Johannesson, M., Johansson, P.-O., \& Löfgren, K.-G. (1997). On the value of changes in life expectancy: Blips versus parametric changes. Journal of Risk and Uncertainty, 15(3), 221-239.

Jones-Lee, M. (1974). The value of changes in the probability of death or injury. Journal of Political Economy, 82(4), 835-849.

Jones-Lee, M. W., Hammerton, M., \& Philips, P. R. (1985). The value of safety: Results of a national sample survey. Economic Journal, 95(377), 49-72.

Jones-Lee, M. W., \& Loomes, G. (1995). Scale and context effects in the valuation of transport safety. Journal of Risk and Uncertainty, 11(3), 183-203.

Kahneman, D. (2011). Thinking, fast and slow. New York: Farrar, Straus, and Giroux.

Kahneman, D., \& Tversky, A. (1979). Prospect theory: An analysis of decision under risk. Econometrica, 47(2), 263-291.

Kaplow, L. (2005). The value of a statistical life and the coefficient of relative risk aversion. Journal of Risk and Uncertainty, 31(1), 23-34.

Keeney, R. L. (1980). Equity and public risk. Operations Research, 28(3-part-i), 527-534.

Keeney, R. (1997). Estimating fatalities induced by the economic costs of regulations. Journal of Risk and Uncertainty, 14(1), 5-23.

Keeney, R. (1990). Mortality risks induced by economic expenditures. Risk Analysis, 10(1), 147-159.

Klibanoff, P., Marinacci, M., \& Mukerji, S. (2005). A smooth model of decision making under ambiguity. Econometrica, 73, 1846-1892.

Kniesner, T. J., Viscusi, W. K., \& Ziliak, J. P. (2010). Policy relevant heterogeneity in the value of statistical life: New evidence from panel data quantile regressions. Journal of Risk and Uncertainty, 40(1), 15-31.

Krupnick, A. (2007). Mortality-risk valuation and age: Stated preference evidence. Review of Environmental Economics and Policy, 1(2), 261-282.

Lindhjem, H., Navrud, S., Braathen, N. A., \& Biausque, V. (2011). Valuing mortality risk reductions from environmental, transport, and health policies: A global meta-analysis of stated-preference studies. Risk Analysis, 31(9), 1381-1407.

Liu, J.-T., Hammitt, J. K., Wang, J.-D., \& Tsou, M.-W. (2005). Valuation of the risk of SARS in Taiwan. Health Economics, 14(1), 83-91.

Loewenstein, G. F., Weber, E. U., Hsee, C. K., \& Welch, E. S. (2001). Risk as feelings. Psychological Bulletin, 127(2), 267-286.

Margolis, H. (1996). Dealing with risk: Why the public and the experts disagree on environmental issues. University of Chicago Press.

Masterman, C. J., \& Viscusi, W. K. (2018). The income elasticity of global values of a statistical life: Stated preference evidence. Journal of Benefit-Cost Analysis, 9(3), 407-434.

McDonald, R. L., Chilton, S. M., Jones-Lee, M. W., \& Metcalf, H. R. T. (2016). Dread and latency impacts on a VSL for cancer risk reductions. Journal of Risk and Uncertainty, 52(2), 137-161.

Murphy, K. M., \& Topel, R. H. (2006). The value of health and longevity. Journal of Political Economy, 114(5), 871-904.

Ng, Y.-K. (1992). The older the more valuable: Divergence between utility and dollar values of life as one ages. Journal of Economics, 55(1), 1-16.

Pratt, J. W., \& Zeckhauser, R. J. (1996). Willingness to pay and the distribution of risk and wealth. Journal of Political Economy, 104(4), 747-763. 
Rheinberger, C. M. (2011). A mixed logit approach to study preferences for safety on alpine roads. Environmental and Resource Economics, 49(1), 121-146.

Rheinberger, C. M., \& Treich, N. (2017). Attitudes toward catastrophe. Environmental and Resource Economics, 67(3), 609-636.

Riddel, M., \& Shaw, W. D. (2006). A theoretically-consistent empirical model of non-expected utility: An application to nuclear-waste transport. Journal of Risk and Uncertainty, 32(2), 131-150.

Robinson, L. A. (2007). How US government agencies value mortality risk reductions. Review of Environmental Economics and Policy, 1(2), 283-299.

Robinson, L.A., \& Hammitt, J.K. (2011). Behavioral economics and the conduct of benefit-cost analysis: Towards principles and standards. Journal of Benefit-Cost Analysis, 2(2), article 5, https://doi.org/10. 2202/2152-2812.1059. Reprinted in S. Farrow \& R.O. Zerbe Jr. (Eds.), Principles and Standards for Benefit-Cost Analysis. Chapter 10, 317-363. Cheltenham, UK: Edward Elgar, 2013.

Robinson, L. A., Raich, W., Hammitt, J. K., \& O’Keeffe, L. (2019). Valuing children's fatality risk reductions. Journal of Benefit-Cost Analysis, 10(2), 156-177.

Rosen, S. (1988). The value of changes in life expectancy. Journal of Risk and Uncertainty, 1(3), $285-304$.

Rothshchild, M., \& Stiglitz, J. (1970). Increasing risk: I. A definition. Journal of Economic Theory, 2(3), 225243.

Schelling, T. C. (1968). The life you save may be your own. In S. Chase (Ed.), Problems in public expenditure analysis (pp. 143-144). Brookings: Washington, D.C.

Shepard, D. S., \& Zeckhauser, R. J. (1984). Survival versus consumption. Management Science, 30(4), 423439.

Shogren, J.F. (2005). Economics of diet and health: Research challenges. Food Economics - Acta Agriculturae Scandinavica, Section C, 2(3,4), 117-127.

Shogren, J. F., \& Thunström, L. (2016). Do we need a new behavioral benchmark for BCA? Journal of Benefit-Cost Analysis, 7(1), 92-106.

Shrime, M. G., Weinstein, M. C., Hammitt, J. K., Cohen, J. L., \& Salomon, J. A. (2018). Trading bankruptcy for health: A discrete-choice experiment. Value in Health, 21(1), 95-104.

Slovic, P., Fischhoff, B., \& Lichtenstein, S. (1984). Behavioral decision theory perspectives on risk and safety. Acta Psychologica, 56(1-3), 183-203.

Slovic, P., Finucane, M., Peters, E., \& MacGregor, D. G. (2004). Risk as analysis and risk as feelings: Some thoughts about affect, reason, risk, and rationality. Risk Analysis, 24(2), 311-322.

Slovic, P. (1987). Perception of risk. Science, 236(4799), 280-285.

Smith, J. E., \& Keeney, R. L. (2005). Your money or your life: A prescriptive model for health, safety, and consumption decisions. Management Science, 51(9), 1309-1325.

Subramanian, U., \& Cropper, M. (2000). Public choices between life saving programs: The tradeoff between qualitative factors and lives saved. Journal of Risk and Uncertainty, 21(1), 117-149.

Thaler, R. (1985). Mental accounting and consumer choice. Marketing Science, 4(3), 199-214.

Thunström, L., Newbold, S. C., Finnoff, D., Ashworth, M., \& Shogren, J. F. (2020). The benefits and costs of using social distancing to flatten the curve for COVID-19. Journal of Benefit-Cost Analysis, 11(2), 179195.

Trautmann, S., \& van de Kuilen, G. (2015). Ambiguity attitudes. The Wiley Blackwell Handbook of Judgment and Decision Making. 89-116. Chichester: Wiley.

Treich, N. (2010). The value of a statistical life under ambiguity aversion. Journal of Environmental Economics and Management, 59(1), 15-26.

Viscusi, W. K. (1994a). Mortality effects of regulatory costs and policy evaluation criteria. RAND Journal of Economics, 225, 94-109.

Viscusi, W. K. (1994b). Risk-risk analysis. Journal of Risk and Uncertainty, 8, 5-18.

Viscusi, W. K. (2009). The devaluation of life. Regulation and Governance, 3(2), 103-127.

Viscusi, W. K. (2010). Policy challenges of the heterogeneity of the value of statistical life. Foundations and Trends in Microeconomics, 6(2), 99-172.

Viscusi, W. K., \& Aldy, J. E. (2003). The value of a statistical life: A critical review of market estimates throughout the world. Journal of Risk and Uncertainty, 27(1), 5-76.

Viscusi, W. K., Magat, W. A., \& Huber, J. (1991). Communication of ambiguous risk information. Theory and Decision, 31(2-3), 159-173.

Viscusi, W. K., \& Masterman, C. J. (2017a). Anchoring biases in international estimates of the value of a statistical life. Journal of Risk and Uncertainty, 54(2), 103-128.

Viscusi, W. K., \& Masterman, C. J. (2017b). Income elasticities and global values of a statistical life. Journal of Benefit-Cost Analysis, 8(2), 226-250. 
Weinstein, M. C., Shepard, D. S., \& Pliskin, J. S. (1980). The economic value of changing mortality probabilities: A decision-theoretic approach. Quarterly Journal of Economics, 94(2), 373-396.

Wildavsky, A. (1979). No risk is the highest risk of all. American Scientist, 67, 32-37.

Wildavsky, A. (1980). Richer is safer. The Public Interest, 60, 23-39.

Publisher's note Springer Nature remains neutral with regard to jurisdictional claims in published maps and institutional affiliations. 